\title{
Outcome of assisted reproductive technology in overweight and obese women
}

\author{
Antonio MacKenna ${ }^{1,2}$, Juan Enrique Schwarze ${ }^{1,3}$, Javier A Crosby ${ }^{1,2}$, Fernando Zegers-Hochschild ${ }^{1,2,4}$ \\ ${ }^{1}$ Latin American Network of Assisted Reproduction \\ ${ }^{2}$ Unit of Reproductive Medicine, Clinica Las Condes, Santiago, Chile \\ ${ }^{3}$ Unit of Reproductive Medicine, Clinica Monteblanco, Santiago, Chile \\ ${ }^{4}$ Program of Ethics and Public Policies in Human Reproduction, University Diego Portales, Santiago, Chile
}

\section{ABSTRACT}

Objective: The main objective of this study was to assess the prevalence of overweight and obesity among patients undergoing assisted reproductive technology (ART) in Latin America and its consequences on treatment outcomes.

Methods: We used the Latin American Registry of ART to obtain women's age and body mass index (BMI), cancellation rate, number of oocytes retrieved and embryos transferred, clinical pregnancy, live birth and miscarriage rates from 107.313 patients undergoing autologous IVF and ICSI during four years; a multivariable analysis was performed to determine the effect of BMI on cancellation, oocytes retrieved, pregnancy, live birth and miscarriage, adjusting for age, number of embryos transferred and embryo developmental stage upon embryo transfer, when appropriate.

Results: The prevalence of overweight and obesity was $16.1 \%$ and $42.4 \%$, respectively; correcting for age of female partner, overweight and obesity were associated to an increase in the odds of cancellation and to a lower mean number of oocytes retrieved; after adjusting for age, number of embryos transferred and stage of embryo development at transfer, we found that the BMI category was not associated to a change in the likelihoods of pregnancy, live birth and miscarriage.

Conclusions: The prevalence of obesity among women seeking ART in Latin America is surprisingly high; however, BMI does not influence the outcome of ART performed in these women.

Keywords: ART, BMI, obesity, clinical pregnancy, live birth, miscarriage

\section{INTRODUCTION}

The prevalence of overweight and obesity, defined by World Health Organization (WHO) as a body mass index (BMI) of $25-30 \mathrm{~kg} / \mathrm{m}^{2}$ and $\geq 30 \mathrm{~kg} / \mathrm{m}^{2}$ (WHO, 2004), respectively, is increasing worldwide as an epidemic, and has become a serious health problem. Rivera et al. (2014) reported that nearly $30 \%$ of the Latin American population is obese. If current trends continue, it is estimated that by the year 2030 up to $80 \%$ of the Latin American and the Caribbean adult population could be overweight or obese (Kelly et al., 2008).

It has been demonstrated that the time required to achieve a spontaneous pregnancy is longer in obese women (Gesink Law et al., 2007) and the probability of pregnancy is reduced by $5 \%$ per unit of BMI exceeding $29 \mathrm{~kg} / \mathrm{m}^{2}$ (van der Steeg et al., 2008). Jungheim \& Moley (2010) suggested that obesity in women increases the risk of infertility by impairing ovulation, oocyte quality, fertilization, embryo quality and implantation. Due to the relationship between higher BMI and infertility, many overweight and obese women must undergo treatment by assisted reproductive technologies (ART). Luke et al. (2011) reported that $23.4 \%$ of the women undergoing ART in the United States of America (USA) during 2007 were overweight and $16.5 \%$ were obese, and Provost et al. (2016) showed a similar prevalence of overweight $(22.9 \%)$ and obesity $(17.8 \%)$ within patients needing ART in USA from 2008 to 2010.

The available evidence about the effects of BMI on the outcome of ART is conflicting. It has been suggested that obese patients require higher doses of gonadotropins, have a lower response to ovarian stimulation, higher cancellation rates, reduced number of oocytes retrieved, poorer oocyte quality, lower fertilization rates, less number of mature oocytes and poorer embryo quality (Pandey et al., 2010). DeUgarte et al. (2010) also showed that women with a BMI $\geq 35 \mathrm{~kg} / \mathrm{m}^{2}$ have lower implantation, pregnancy and live birth rates than women with BMI $<35 \mathrm{~kg} / \mathrm{m}^{2}$. Moreover, Luke et al. (2011) found reduced pregnancy rates with autologous but not with donor oocytes in obese women, suggesting impaired oocytes and poor embryo quality.

A recent report based on data from the Society for Assisted Reproductive Technology Registry (SART) showed that the prevalence of overweight and obesity was $22.9 \%$ and $17.8 \%$, respectively, and pregnancy outcomes were more favorable in women with normal BMI, and it worsens as BMI increases (Provost et al., 2016).

There are no studies regarding the prevalence of overweight and obesity among women undergoing ART in Latin America and its consequences on treatment outcomes. The main objective of this study was to obtain this missing evidence.

\section{MATERIALS AND METHODS}

Data was obtained from the Latin American Registry of ART (RLA). The RLA collects information from centers in fifteen Latin American countries. Patients admitted for autologous in vitro fertilization (IVF) and intra-cytoplasmic sperm injection (ICSI) with fresh embryo transfer started between January $1^{\text {st }}, 2010$ and December $31^{\text {st }}, 2014$, and babies born up to September of 2015, were included in this study.

As part of the accreditation process, all participating institutions agreed to have their data registered and published by the RLA (Zegers-Hochschild et al., 2016). Data used for the current study were women's ages, weights and heights, cancellation rates, numbers of oocytes retrieved, numbers of embryos transferred, clinical pregnancy rates and live birth rates per initiated cycle, and miscarriage rates (following RLA rules, there was no missing information). We used the terminology published by the International Committee Monitoring Assisted Reproductive Technologies (ICMART) and the WHO 2009 glossary (Zegers-Hochschild et al., 2009). 
BMI was calculated by dividing body mass (weight in kilograms) by the square of body height in meters. We stratified BMI in four categories, according to the WHO classification (WHO, 2004): BMI $\leq 18.4 \mathrm{~kg} / \mathrm{m}^{2}$ (underweight), $18.5-24.9 \mathrm{~kg} / \mathrm{m}^{2}$ (normal weight), BMI $25-$ $30 \mathrm{~kg} / \mathrm{m}^{2}$ (overweight) and BMI $\geq 30 \mathrm{~kg} / \mathrm{m}^{2}$ (obese).

The parametric data was described as means and standard deviation, and non-parametric data by median and ranges. To compare differences in groups we used the Chi square test and the Mann-Whitney-u test for categorical and non-parametric variables, respectively.

We performed a multivariable analysis to determine the effects of BMI on cancellation, number of oocytes retrieved, pregnancy, live birth and miscarriage rates, adjusting for age, number of embryos transferred and embryo developmental stage upon embryo transfer (embryos at cleavage stage or blastocysts), when appropriate. Results from women with normal BMI were used as the reference group. A $p$-value below 0.01 was considered statistically significant.

\section{RESULTS}

We analyzed a total of 107.313 patients admitted for autologous IVF and ICSI, who underwent ovulation induction for ART in Latin America during the study period. All patients with initiated cycles were included in the study, therefore some of them were cancelled previous oocyte retrieval, other cancelled because lack of fertilization or embryo development and the vast majority of them reached fresh embryo transfer, either of cleavage stage embryos or blastocysts (no frozen embryo transfers were included). Their mean age ( $\pm S D$ ) was $36.4 \pm 4.6$ years old and their prevalence rates regarding overweight and obesity were $16.1 \%$ and $42.4 \%$, respectively.

Table 1 shows the women's ages, cancellation rates, numbers of oocytes and the numbers of embryos transferred in each BMI category. No significant difference was found in age and number of embryos transferred between the categories. Clinical pregnancy rates and live birth rates per initiated cycle and miscarriage rates in each BMI category are shown on table 2. If no adjustments are made for women's ages, numbers of embryos transferred and the stages of embryo development at transfer, the pregnancy and live birth rates become statistically lower in obese patients when compared with women having normal BMIs. Miscarriage rates varied from $15.9 \%$ to $18.4 \%$, without differences according to BMI category.

Table 3 shows the outcomes of the multivariable analyses. Correcting for age of the female partner, overweight and obesity were associated to an increase in the likelihood of cancellation and to a lower mean number of oocytes retrieved, when compared to those with normal BMIs. On the other hand, after adjusting for confounding variables such as age, number of embryos transferred and stage of embryo development upon transfer, we found that the BMI category was not associated with changes in the likelihoods of pregnancy, live birth and miscarriage.

\section{DISCUSSION}

We found that the proportion of overweight and obese women treated with ART in Latin America between 2010 and 2014 reached $16.1 \%$ and $42.4 \%$, respectively. Intentionally, we decided to assess results per women with initiated cycles, because such analysis offers better epidemiological information for healthcare providers who must counsel their patients. Consequently, we found that an increase in BMI was associated to an increase in cancellation and a reduced number of retrieved oocytes, but did not affect the odds of clinical pregnancy, live birth and miscarriage.
The main strength of our study is the large number of cases and the thoroughness of the RLA database that allows adjustment for the most relevant confounding variables. It also represents results from different centers located in different countries, thus conferring external validity. However, potential limitations of the current study are that we did not consider the possible effect of the male partner and polycystic ovary syndrome, more commonly diagnosed among obese women, on ART outcomes; although Provost et al. (2016) recently suggested that it is the BMI itself, rather than the underlying pathologies, that contributes to the outcomes.

The prevalence of obese patients among Latin American women undergoing ART is surprisingly higher than in any other report published so far. Indeed, in the other large multicentric studies, undertaken in the USA, only $16.5 \%$ and $17.8 \%$ of patients undergoing ART were obese (Luke et al., 2011; Provost et al., 2016). This issue could be explained because of the rapid epidemiological changes in most developing countries over the last decades, with a nutritional transition, which impacts on the quality of food, resulting in a declining of malnutrition rates, but an increase in overweight and obesity (Rivera et al., 2004), due to a change in dietary intake and energy expenditure, influenced by demographic, environmental, economic, psychosocial and cultural factors (Barria \& Amigo, 2006). Sedentary behavior and highly caloric diets, with an increase intake of processed foods containing large amounts of refined sugars and saturated fats, have been described as the main causes of obesity in Latin America and other developing countries (Pearson et al., 2014; Popkin et al., 2012).

The group of overweight and obese women in our study had significantly more cycles cancelled. They also had significantly less oocytes retrieved, if compared with women with normal BMI, and correcting by age, although this is of little clinical significance. Cancellation rates were four-fold higher in obese patients than in women with a BMI $<30 \mathrm{~kg} /$ $\mathrm{m}^{2}$; however, this was much lower than cancellation rates reported by Provost et al. (2016). Pinborg et al. (2011) also showed an increase in the likelihood of cycle cancellation, after adjusting for age. Moreover, Pinborg et al. (2011) and Zander-Fox et al. (2012) also reported a significantly lower number of oocytes retrieved in obese patients.

In our study, after adjusting for known confounding factors (age, number of embryos transferred and stage of embryo development upon transfer), overweight and obesity were not associated with a decrease in the odds of pregnancy and live birth or an increase in the odds of miscarriage. Several studies have reported that women with overweight and obesity undergoing ART have lower pregnancy and/or live birth rates, when compared with patients with normal BMI (Tamer Erel \& Senturk, 2009; Orvieto et al., 2009; Bellver et al., 2010; Rittenberg et al., 2011; Singh et al., 2012; Chavarro et al., 2012; Provost et al., 2016). Moreover, the meta-analysis performed by Rittenberg et al. (2011) also showed increased miscarriage rates in obese patients undergoing ART. On the other hand, other authors have reported no changes in ART outcomes within different BMI categories (Sathya et al., 2010; Vilarino et al., 2011; Zander-Fox et al., 2012). However, none of these studies adjusted results for known confounding factors, i.e. woman's age, number of embryos transferred and stage of embryo development upon transfer. If the results from the current study are analyzed without considering these variables, it also shows a significant difference between women with normal weight and obese patients, but this difference disappears when a multivariable analysis is performed to adjust results for confounding variables. 
Table 1. Age, cancellation rates, number of oocytes retrieved and number of embryos transferred in women undergoing 107.313 cycles of autologous FIV/ICSI, according to BMI

\begin{tabular}{|l|c|c|c|c|}
\hline BMI & $\leq 18.4$ & $18.5-24.9$ & $25.0-29.9$ & $\geq 30.0$ \\
\hline No cycles & 1.436 & 43.130 & 17.247 & 45.500 \\
\hline Age (years) $*$ & $35.0 \pm 4.6$ & $35.8 \pm 4.5$ & $36.0 \pm 4.6$ & $36.0 \pm 4.6 \S$ \\
\hline Cancellation rates (\%) & 2.14 & $2.08(\mathrm{~A})$ & 2.51 & $5.7(\mathrm{~B})$ \\
\hline No $^{+}$ & $9.1(0-58)$ & $8.9(0-80)(\mathrm{C})$ & $9.0(0-70)$ & $8.1(0-73)(\mathrm{D})$ \\
\hline No embryos retrieved $^{*}$ & $2.1(1-6)$ & $2.1(1-6)$ & $2.1(1-5)$ & $2.1(1-6) \S$ \\
\hline
\end{tabular}

* Means \pm SD. (A) vs (B) $p<0.0001 ;{ }^{+}$Per initiated cycle.(C) vs (D) $p<0.0001 ;{ }^{*}$ Medians (ranges). ${ }^{\S}$ NS.

Table 2. Clinical pregnancy, live birth and miscarriage rates in women undergoing 107.313 cycles of autologous FIV/ICSI, according to BMI

\begin{tabular}{|l|c|c|c|c|}
\hline BMI & $\leq 18.4$ & $18.5-24.9$ & $25.0-29.9$ & $\geq 30$ \\
\hline No $^{\circ}$ cycles & 1.436 & 43.130 & 17.247 & 45.500 \\
\hline Pregnancy rates (\%) $*$ & 25.83 & $25.52(\mathrm{~A})$ & 26.53 & $23.27(\mathrm{~B})$ \\
\hline Live birth rates (\%) $*$ & 21.24 & $20.55(\mathrm{C})$ & 21.32 & $18.68(\mathrm{D})$ \\
\hline Miscarriage rates (\%) & 15.90 & 17.98 & 18.40 & $18.33^{+}$ \\
\hline
\end{tabular}

* Per initiated cycle; (A) vs (B) $p<0.0001 ;{ }^{+}$NS.; (C) vs (D) $p<0.0001$.

Table 3. Multivariable analysis adjusting for age, number of embryos transferred and stage of embryo development upon transfer on predictors of ART outcome, according to abnormal BMI categories in women undergoing $107.313 \mathrm{cycles}$ of autologous FIV/ICSI

\begin{tabular}{|l|c|c|c|c|c|}
\hline & Cancellation* & $\begin{array}{c}N^{\circ} \text { oocytes } \\
\text { retrieved }\end{array}$ & Pregnancy $^{*}$ & Live birth $^{*}$ & Miscarriage $^{*}$ \\
\hline $\begin{array}{l}\text { Underweight BMI } \\
\leq 18.4\left(\mathrm{~kg} / \mathrm{m}^{2}\right)\end{array}$ & $\begin{array}{c}\text { OR } 1.00(0.68 \text { to } \\
1.46) p=0.995\end{array}$ & $\begin{array}{c}\beta-0.27(-0.62 \text { to } \\
0.08) p=0.695\end{array}$ & $\begin{array}{c}\text { OR } 1.03(0.91 \text { to } \\
1.18) p=0.629\end{array}$ & $\begin{array}{c}\text { OR } 1.04(0.91 \text { to } \\
1.20) p=0.552\end{array}$ & $\begin{array}{c}\text { OR } 0.94(0.79 \text { to } \\
1.26) p=0.695\end{array}$ \\
\hline $\begin{array}{l}\text { Overweight BMI } \\
25-29.9\left(\mathrm{~kg} / \mathrm{m}^{2}\right)\end{array}$ & OR $1.18(1.05$ to & $\begin{array}{c}\beta 0.20(0.08 \text { to } \\
0.32 p=0.005\end{array}$ & $\begin{array}{c}\text { OR } 1.00(0.96 \text { to } \\
1.05) p=0.811\end{array}$ & $\begin{array}{c}\text { OR } 1.0(0.95 \text { to } \\
1.05) p=0.927\end{array}$ & $\begin{array}{c}\text { OR } 1.0(0.92 \text { to } \\
1.10) p=0.881\end{array}$ \\
\hline Obesity BMI & OR $2.78(2.58$ to & $\begin{array}{c}\beta-0.79(-0.88 \text { to } \\
\geq 30\left(\mathrm{~kg} / \mathrm{m}^{2}\right)\end{array}$ & $\begin{array}{c}\text { OR } 0.96(0.93 \text { to } \\
1.00) p=0.025\end{array}$ & $\begin{array}{c}\text { OR } 0.96(0.93 \text { to } \\
0.99) p=0.039\end{array}$ & $\begin{array}{c}\text { OR } 1.01(0.95 \text { to } \\
1.09) p=0.693\end{array}$ \\
\hline
\end{tabular}

* Results are adjusted for age and presented as odd ratios (95\% confidence interval) and $p$-value. + Results are adjusted for age and presented as coefficient $\beta$ of medians ( $95 \%$ confidence interval) and $p$-value. $\neq$ Results are adjusted for age, number of embryos transferred and embryo stage at embryo transfer and presented as odd ratios ( $95 \%$ confidence interval) and $p$-value.

Some authors have used multivariable analyses to adjust results for confounding variables: Sneed et al. (2008) adjusted results for age and showed that BMI did not have a major effect on ART outcome; Pinborg et al. (2011) corrected results for age, social class, diagnosis and duration of infertility, demonstrating that pregnancy and live birth rates were significantly lower in obese women undergoing their first ART cycle; Petersen et al. (2013) adjusted results for age and smoking, reporting reduced live birth rates as BMI increased; and Schliep et al. (2015) corrected results for age and parity, showing no differences in ART success among different BMI categories. Moreover, Veleva et al. (2008) adjusting results for age, diagnosis and history of miscarriage, reported an increased risk of miscarriage in women with overweight and obesity. However, none of these authors adjusted results for woman's age, number of embryos transferred and stage of embryo development upon transfer together, as we did in our study.

Furthermore, Luke et al. (2011), Provost et al. (2016) and Moragianni et al. (2012) used multivariable analyses to correct results for several confounding variables including age, number of embryos transferred and day of embryo transfer. The first two authors used data from the SART registry and showed that an increased BMI was associated with significantly greater odds of failure to achieve clinical intrauterine pregnancy and live birth. Provost et al. (2016) also reported significantly higher miscarriage rates with increasing BMI categories. Using data from a single center, Moragianni et al. (2012) showed that the odds of clinical pregnancy and live births were lower and the odds of miscarriage were higher in women with BMI $\geq 30 \mathrm{~kg} / \mathrm{m}^{2}$. These authors concluded that higher BMI is associated with a significant impairment on ART outcomes. We could not reach the same conclusions, which may be due to a possible role of ethnicity on ART results. All these studies were performed in the USA and Luke et al. (2011), the only author reporting ethnicity, had $6 \%$ of Hispanic women among their subjects, against most Hispanic women in our study, which was not registered, for demographic reasons, but expected. In a recent systematic review, performed by Humphries et al. (2016), the authors concluded that there are significant disparities in pregnancy and live birth rates after ART by ethnicity; however, most available studies are limited by sample size, selection bias (different definitions of race and ethnicity), extensive missing data and inadequate adjustment for confounding variables. 
On the other hand, given the high prevalence of obesity among women undergoing ART in Latin America, patients have to be aware of the maternal and neonatal risks derived from obesity and should be advised to lose weight before undergoing ART. Recently, a large cohort study showed that relative risks of gestational diabetes, preeclampsia, fetal macrosomia, cesarean delivery, blood loss, neonatal hypoglycemia and respiratory distress syndrome increase as BMI increases over $25 \mathrm{~kg} / \mathrm{m}^{2}$ (Schuster et al., 2016). Moreover, Koning et al. (2010) suggested that overweight and obesity in ovulatory infertile women leads to a $44 \%$ and $70 \%$ increase in costs due to pregnancy complications, respectively. A recently published study by Kaye et al. (2016) suggested how relevant it is to develop reasonable standards of care for obese patients, to encourage them to lose weight before undergoing fertility treatment, giving priority to safety and overall health status, although patient's autonomy must be balanced with non-maleficence and the avoidance of interventions that may be unsafe both immediately and in the long run.

In summary, we found that BMI does not influence the outcomes of ART performed in Latin American women, nevertheless, considering maternal and neonatal risks, overweight and obese patients should be advised to lose weight before undergoing ART. Future studies are needed to assess the role of ethnicity on ART results and the underlying causes of trans-ethnical differences on outcomes between women having similar BMI.

\section{ACKNOWLEDGEMENTS}

Thanks to Carolina Musri, the RLA administrator, and all members of centers reporting to RLA for their efforts, which enabled this study.

\section{CONFLICT OF INTERESTS}

The authors have no conflict of interests to report.

\section{Corresponding author:}

Antonio MacKenna

Unit of Reproductive Medicine, Clinica Las Condes

Santiago, Chile

E-mail: amackenn@clc.cl

\section{REFERENCES}

Barria RM, Amigo H. Nutrition transition: a review of Latin American profile. Arch Latinoam Nutr. 2006;56:3-11. PMID: 16786728

Bellver J, Ayllón Y, Ferrando M, Melo M, Goyri E, Pellicer A, Remohí J, Meseguer M. Female obesity impairs in vitro fertilization outcome without affecting embryo quality. Fertil Steril. 2010;93:447-54. PMID: 19171335 DOI: 10.1016/j.fertnstert.2008.12.032

Chavarro JE, Ehrlich S, Colaci DS, Wright DL, Toth $\mathrm{TL}$, Petrozza JC, Hauser R. Body mass index and short-term weight change in relation to treatment outcomes in women undergoing assisted reproduction. Fertil Steril. 2012;98:109-16. PMID: 22607889 DOI: $10.1016 /$ j.fertnstert.2012.04.012

DeUgarte D, DeUgarte C, Sahakian V. Surrogate obesity negatively impacts pregnancy rates in third-party reproduction. Fertil Steril. 2010;93:1008-10. PMID: 19733847 DOI: 10.1016/j.fertnstert.2009.07.1005
Gesink Law DC, Maclehose RF, Longnecker MP. Obesity and time to pregnancy. Hum Reprod. 2007;22:414-40. PMID: 17095518 DOI: $10.1093 /$ humrep/del400

Humphries LA, Chang O, Humm K, Sakkas D, Hacker MR. Influence of race and ethnicity on in vitro fertilization outcomes: systematic review. Am J Obstet Gynecol. 2016;214:212e1-212e17. PMID: 26363483 DOI: 10.1016/j.ajog.2015.09.002

Jungheim ES, Moley KH. Current knowledge of obesity's effects in the pre- and periconceptional periods and avenues for future research. Am J Obstet Gynecol. 2010;203:52530. PMID: 20739012 DOI: 10.1016/j.ajog.2010.06.043

Kaye L, Sueldo C, Engmann L, Nulsen J, Bendiva CA. Survey assessing obesity policies for assisted reproductive technology in the United States. Fertil Steril. 2016;105:703-6.e2. PMID: 26690012 DOI: $10.1016 /$ j.fertnstert.2015.11.035

Kelly T, Yang W, Chen CS, Reynolds K, He J. Global burden of obesity in 2005 and projections to 2030. Int J Obes (Lond). 2008;32:1431-7. PMID: 18607383 DOI: $10.1038 /$ ijo. 2008.102

Koning AM, Kuchenbecker WK, Groen $H$, Hoek A, Land JA, Khan KS, Mol BW. Economic consequences of overweight and obesity in infertility: a framework for evaluating the costs and outcomes of fertility care. Hum Reprod Update. 2010;16:246-54. PMID: 20056674 DOI: $10.1093 /$ humupd/dmp053

Luke B, Brown MB, Stern JE, Missmer SA, Fujimoto VY, Leach R; SART Writing Group. Female obesity adversely affects assisted reproductive technology (ART) pregnancy and live birth rates. Hum Reprod. 2011;26:245-52. PMID: 21071489 DOI: $10.1093 /$ humrep/deq306.

Moragianni VA, Jones SM, Ryley DA. The effect of body mass index on the outcomes of first assisted reproductive technology cycles. Fertil Steril. 2012;98:102-8. PMID: 22584023 DOI: 10.1016/j.fertnstert.2012.04.004

Orvieto R, Meltcer S, Nahum R, Rabinson J, Anteby EY, Ashkenazi $J$. The influence of body mass index on in vitro fertilization outcome. Int J Gynaecol Obstet. 2009;104:535. PMID: 18957271 DOI: 10.1016/j.ijgo.2008.08.012

Pandey S, Pandey S, Maheshwari A, Bhattacharya S. The impact of female obesity on the outcome of fertility treatment. J Hum Reprod Sci. 2010;3:62-7. PMID: 21209748 DOI: $10.4103 / 0974-1208.69332$

Pearson N, Braithwaite RE, Biddle $\mathrm{SJH}$, van Sluijs EM, Atkin AJ. Associations between sedentary behaviour and physical activity in children and adolescents: a metaanalysis. Obes Rev. 2014;15:666-75. PMID: 24844784 DOI: $10.1111 /$ obr.12188

Petersen GL, Schmidt L, Pinborg A, Kamoer-Jørgensen $M$. The influence of female and male body mass index on live birth after assisted reproductive technology treatment: a nationwide register-based cohort study. Fertil Steril. 2013;99:1654-62. PMID: 23394781 DOI: $10.1016 /$ j.fertnstert.2013.01.092 
Pinborg A, Gaarslev C, Hougaard CO, Nyboe Andersen $A$, Andersen PK, Boivin J, Schmidt L. Influence of female bodyweight on IVF outcome: a longitudinal multicenter cohort study of 487 infertile couples. Reprod Biomed Online. 2011;23:490-9. PMID: 21856228 DOI: $10.1016 /$ j.rbmo.2011.06.010

Popkin BM, Adair LS, Ng SW. Global nutrition transition and the pandemic of obesity in developing countries. Nutr Rev. 2012;70:3-21. PMID: 22221213 DOI: $10.1111 / j .1753-4887.2011 .00456 . x$

Provost MP, Acharya KS, Acharya CR, Yeh JS, Steward RG, Eaton JL, Goldfarb JM, Muasher SJ. Pregnancy outcomes decline with increasing body mass index: analysis of 239,127 fresh autologous in vitro fertilization cycles from the 2008-2010 Society for Assisted Reproductive Technology registry. Fertil Steril. 2016;105:663-9. PMID: 26627120 DOI: $10.1016 /$ j.fertnstert.2015.11.008

Rittenberg V, Seshadri S, Sunkara SK, Sobaleva S, OtengNtim E, El-Toukhy T. Effect of body mass index on IVF treatment outcome: an updated systematic review and meta-analysis. Reprod Biomed Online. 2011;23:421-39. PMID: 21885344 DOI: 10.1016/j.rbmo.2011.06.018

Rivera JA, Barquera S, González-Cossío T, Olaiz G, Sepúlveda J. Nutrition transition in Mexico and in other Latin American countries. Nutr Rev. 2004;62:S149-57. PMID: 15387482 DOI: https://doi.org/10.1111/j.1753-4887.2004.tb00086.x

Rivera JA, de Cossío, TG, Pedraza LS, Aburto TC, Sánchez TG, Martorell R. Childhood and adolescent overweight and obesity in Latin America: a systematic review. Lancet Diabetes Endocrinol. 2014;2:321-32. PMID: 24703050 DOI: $10.1016 / S 2213-8587(13) 70173-6$

Sathya A, Balasubramanyam S, Guota S, Verma T. Effect of body mass index on in vitro fertilization outcomes in women. J Hum Reprod Sci. 2010;3:135-8. PMID: 21234174 DOI: $10.4103 / 0974-1208.74155$

Schliep KC, Mumford SL, Ahrens KA, Hotaling JM, Carrell DT, Link M, Hinkle SN, Kissell K, Porucznik CA, Hammoud AO. Effect of male and female body mass index on pregnancy and live birth success after in vitro fertilization. Fertil Steril. 2015;103:388-95. PMID: 25497445 DOI: 10.1016/j.fertnstert.2014.10.048

Schuster M, Mackeen AD, Neubert AG, Kirchner $H L$, Paglia MJ. The impact of pre-pregnancy body mass index and pregnancy weight gain on maternal and neonatal outcomes. Obstet Gynecol. 2016;127:17s. DOI: $10.1097 / 01$. AOG.0000483316.73003.97

Singh N, Gupta P, Mittal S, Malhotra N. Correlation of body mass index with outcome of in vitro fertilization in a developing country. Arch Gynecol Obstet. 2012;285:25963. PMID: 21792549 DOI: $10.1007 /$ s00404-011-2013-8
Sneed $M L$, Uhler $M L$, Grotjan $H E$, Rapisarda JJ, Lederer $\mathrm{KJ}$, Beltsos AN. Body mass index: impact on IVF success appears age-related. Hum Reprod. 2008;23:1835-9. PMID: 18503054 DOI: $10.1093 /$ humrep/den 188

Tamer Erel C, Senturk LM. The impact of body mass index on assisted reproduction. Curr Opin Obstet Gynecol. 2009;21:228-35. PMID: 19395966 DOI: $10.1097 /$ GCO.0b013e32832aee96

van der Steeg JW, Steures P, Eijkemans MJ, Habbema JD, Hompes PG, Burggraaff JM, Oosterhuis GJ, Bossuyt PM, van der Veen F, Mol BW. Obesity affects spontaneous pregnancy chances in subfertile, ovulatory women. Hum Reprod. 2008;23:324-8. PMID: 18077317 DOI: $10.1093 /$ humrep/dem 371

Veleva Z, Titinem A, Vislka S, Hydén-Granskog C, Tomás C, Martikainen $\mathrm{H}$, Tapanainen JS. High and low BMI increase the risk of miscarriage after FIV/ICSI and FET. Hum Reprod. 2008;23:878-84. PMID: 18281684 DOI: $10.1093 /$ humrep/den017

Vilarino FL, Christofolini DM, Rodrigues D, de Souza AM, Christofolini J, Bianco B, Barbosa CP. Body mass index and fertility: in there a correlation with human reproduction outcomes? Gynecol Endocrinol. 2011;27:232-6. PMID: 20528211 DOI: $10.3109 / 09513590.2010 .490613$

WHO expert consultation. Appropriate body-mass index for Asian population and its implications for policy and intervention strategies. Lancet. 2004;363:157-63. PMID: 14726171 DOI: $10.1016 /$ S0140-6736(03)15268-3

Zander-Fox DL, Henshaw R, Hamilton H, Lane M. Does obesity really matter? The impact of BMI on embryo quality and pregnancy outcomes after IVF in women age $\leq 38$ years. Aust N Z J Obstet Gynaecol. 2012;52:270-6. PMID: 22694077 DOI: 10.1111/j.1479-828X.2012.01453.x

Zegers-Hochschild F, Adamson GD, de Mouzon J, Ishihara O, Mansour R, Nygren K, Sullivan E, Vanderpoel S; International Committee for Monitoring Reproductive Technology; World Health Organization. International Committee for Monitoring Assisted Reproductive Technology (ICMART) and the World Health Organization (WHO) revised glossary of ART terminology, 2009. Fertil Steril. 2009;92:1520-4. PMID: 19828144 DOI: 10.1016/j.fertnstert.2009.09.009

Zegers-Hochschild F, Schwarze JE, Crosby JA, Musri C, Urbina MT; Latin American Network of Assisted Reproduction (REDLARA). Assisted reproductive techniques in Latin America: the Latin American Registry, 2013. Reprod Biomed Online. 2016;32:614-25. PMID: 26997476 DOI: 10.1016/j.rbmo.2016.02.012 